Preprint: Paper accepted for publication in American Journal of Agricultural Economics

(April 2014)

\title{
Capitalized amenity value of native vegetation in a multifunctional rural landscape
}

\author{
Maksym Polyakov, David Pannell, Ram Pandit, Sorada Tapsuwan and Geoff Park*
}

\begin{abstract}
In many parts of the world, natural vegetation has been cleared to allow agricultural production. To ensure a long-term flow of ecosystem services without compromising agricultural activities, restoration of the environment requires a balance between public and private benefits and costs. Information about private benefits
\end{abstract}

\footnotetext{
* Maksym Polyakov is a research assistant professor, Centre for Environmental Economics and Policy, School of Agricultural and Resource Economics, University of Western Australia, Crawley, Western Australia, Australia. David Pannell is a Winthrop Professor and director, Centre for Environmental Economics and Policy, School of Agricultural and Resource Economics, University of Western Australia, Crawley, Western Australia, Australia. Ram Pandit is an assistant professor, School of Agricultural and Resource Economics, University of Western Australia, Crawley, Western Australia, Australia. Sorada Tapsuwan is a resource economist, CSIRO Ecosystem Science, Wembley, Western Australia, Australia. Geoff Park is a director, Natural Decisions Pty Ltd, Bendigo, Victoria, Australia. This research was conducted with the support of funding from the Australian Research Council Centre of Excellence for Environmental Decisions, the Australian National Environmental Research Program's Environmental Decisions Hub, and the CSIRO Water for Healthy Country Flagship. We acknowledge North Central Catchment Management Authority for providing VicMap Property GIS data. Finally, we are grateful to two anonymous reviewers for their insightful comments.
} 
generated by environmental assets can be utilized in the identification of conservation opportunities on private lands, evaluation of environmental projects, and in the design of effective policy instruments. We use a spatio-temporal hedonic model to estimate private benefits of native vegetation on rural properties in the state of Victoria, Australia. Specifically, we estimate the marginal value of native vegetation on private land and examine how it varies with the extent of vegetation on a property and across a range of property types and sizes. Private benefits of native vegetation are greater per unit area on small and medium-sized properties and smaller on large production-oriented farms. Native vegetation exhibits diminishing marginal benefits as its proportion of a property increases. The current extent of native vegetation cover is lower than the extent that would maximize the amenity value to many landowners. There is a scope for improved targeting of investment in the study region by incorporating private benefits of environmental projects into environmental planning processes. Landowners with high marginal private benefits from revegetation would be more willing to participate in a revegetation program. Targeting those landowners would likely to provide higher value for money, because such projects could be implemented at lower public cost.

Keywords: covariogram; ecological restoration; ecosystem services; non-market valuation; private benefit; rural landscape; spatio-temporal hedonic model

JEL Classification: Q15, Q57 
Native woody vegetation is an important environmental asset in heavily-cleared agricultural landscapes of Australia. It provides a variety of benefits or ecosystem services to both private landowners and the public. Private benefits include shade for livestock, recreational opportunities and increased amenity through improved aesthetics. Examples of public benefits are biodiversity support and regulation of water flows. Since European settlement, one third of Australia's woodlands have been cleared (Olsen et al. 2005 ) resulting in loss of important ecosystem services. There would likely be benefits from preventing further losses and perhaps reversing past losses by restoring native vegetation and rebuilding functioning landscapes (Thomson et al. 2009).

Approximately $77 \%$ of Australian land area is managed by private landholders, which makes conservation on private lands an integral part of Australia's conservation strategy. Effective conservation on private lands would not be possible without identification of the drivers of landowners' participation in conservation programs (Blackmore and Doole 2013). Information on private benefits generated by native vegetation is important for the identification of conservation opportunities on private lands (Raymond and Brown 2011) and for designing effective natural resource management policy instruments for such landscapes (Pannell 2008), particularly for ecological restoration purposes. The optimal re-allocation of agricultural land for ecological restoration depends on the balance between public and private benefits from restoration, and the costs of that restoration, including the opportunity cost of foregone agricultural production. The value of private benefits generated by environmental assets, 
such as native vegetation, is capitalized in property values and can be estimated using the hedonic pricing method.

These issues are highly relevant to current Australian policies. For example, in 2009 the Victorian Government released a long-term strategic framework "Securing Our Natural Future", which emphasizes building healthy and resilient ecosystems by integrating environmental and productivity outcomes in rural and agricultural lands (DSE 2009). Protection and restoration of native vegetation is a key part of the strategy. Similarly, at the national level, Australia's Biodiversity Conservation Strategy (Australian National Biodiversity Strategy Review Task Group 2010) states that $1,000 \mathrm{~km}^{2}$ of fragmented agricultural landscapes and aquatic systems should be restored to improve ecological connectivity by 2015 .

To date, there have been few studies that investigate the values of ecosystem services (e.g. recreation and aesthetics) generated by environmental assets located on private rural lands. For example, Bastian et al. (2002) and Torell et al. (2005) found that wildlife habitat, angling opportunities, and scenic vistas have positive impacts on the value of remote agricultural lands in Wyoming and New Mexico. Sengupta and Osgood (2003) identified that greenness, indicating amount of vigorously growing green vegetation, increases the value of ranchettes in Arizona. Ma and Swinton (2011) found that both on-property and off-property environmental assets, such as forest, wetlands, and streams, increase the value of rural properties in Michigan. Walpole and Lockwood (1999) measured the effect of native remnant vegetation on the values of rural properties in North-East Victoria and Southern New South Wales, Australia. They did not find a 
measureable impact of native remnant vegetation on property value when it covered less than $50 \%$ of property area; however, coverage above $50 \%$ decreased property value. Polyakov et al. (2013) estimated that the value of native vegetation on lifestyle properties in Victoria, Australia, has positive and diminishing marginal implicit price, with the property value maximized when the proportion of area occupied by native vegetation is approximately $40 \%$. The majority of these studies focused on estimating the value of environmental assets on a particular type of property. Only two studies (Ma and Swinton 2011; Walpole and Lockwood 1999) have valued environmental assets on multiple property types (from rural residential properties to commercial farms). However, none of these studies has tested whether there are structural shifts in the parameters of the model due to property types and sizes, and none has quantified the diminishing marginal value of environmental assets on rural properties. In this article, we address this gap in the literature. Methodologically, we also contribute to the existing spatial hedonic modelling literature by simultaneously controlling for spatio-temporal lag, spatial exogenous lag, and spatial error dependencies present in the data.

The purpose of this study is to estimate the value of private benefits generated by environmental assets in a multifunctional rural landscape. Specifically, we estimate the marginal value of native vegetation on private land and examine whether the marginal value varies with the extent of vegetation on a property and across a range of property sizes. We hypothesize that the marginal value of native vegetation on the property diminishes with the amount of native vegetation because it competes for available space with other land uses such as agricultural production. Furthermore, in multifunctional rural 
landscapes, different landowners have different goals for their properties, and many have multiple goals. Typically, smaller (lifestyle) properties are managed mainly for amenity benefits, large properties are managed mostly for agricultural production and mediumsized properties (also known as part-time or hobby farms) are managed for a combination of these benefits. Therefore, we hypothesize that the marginal value of native vegetation, which provides amenity values, will also change with property size, decreasing as the property becomes larger because of the shift in importance between amenity and production goals. Information about private benefits of environmental assets in rural landscapes is important for contemporary conservation policies because it contributes to improved targeting of investment, the need for which has been highlighted in the policy debate over the past decade (e.g., Hajkowicz 2009).

In the following sections we set up a spatial hedonic model to estimate values of environmental assets, describe the study area, data sources and an empirical model, present and discuss results, and summarize key conclusions of the study.

\section{Spatio-temporal hedonic model}

The hedonic pricing method is a revealed-preference non-market valuation method that allows estimation of implicit prices of the utility-bearing characteristics of a differentiated market good (Rosen 1974). We assume that the price of a rural property is determined by its production and consumption characteristics. Characteristics related to agricultural production A depend on provisioning, supporting, and regulating ecosystem services. Consumption characteristics include human-built characteristics $\mathbf{B}$ and ecosystem services $\mathbf{E}$ that provide cultural, recreational, and aesthetic amenity values to 
the landowners. Furthermore, both production and consumption characteristics are affected by location $\mathbf{L}$ relative to population centers and markets, as well as other amenities in a landscape. The empirical model could be formulated as

$$
\mathbf{P}=\alpha+\mathbf{X}^{\prime} \boldsymbol{\beta}+\boldsymbol{\varepsilon},
$$

where $\alpha$ is the intercept; $\mathbf{X}$ is the matrix of explanatory variables consisting of the matrices $\mathbf{A}, \mathbf{B}, \mathbf{E}$ and $\mathbf{L} ; \boldsymbol{\beta}$ is the vector of parameters to be estimated; and $\boldsymbol{\varepsilon}$ is the error term.

Hedonic models use data that are characterized by spatial dependencies among observations (Anselin 1988). Three types of spatial interaction effects that might exist in spatial models were identified by Manski (1993) as correlated, endogenous, and exogenous. The model that has all three spatial interaction effects is commonly referred to as "Manski model" (Elhorst 2010). We hypothesize that all three spatial interaction effects exist in our data. First, there are important variables that are not observed or are measured with error, such as soil quality and precipitation. They are spatially correlated and affect land value. Secondly, characteristics of neighboring properties (explanatory variables of neighboring observations) do influence the value of the property in question. For example, for a lifestyle property it makes a difference whether it is surrounded by similar lifestyle properties or by large agricultural properties, or whether surrounding properties are covered with native vegetation that provides amenity value. Finally, the sale price of a property is affected by the sale prices of properties in the neighborhood beyond the shared property characteristics resulting in a spatial lag relationship. This contradicts the idea underlying the hedonic method that the value of a composite good is 
determined by its characteristics, but in reality this occurs when collecting information is costly and potential buyers use comparable sales from previous time periods to determine the value of the property (Maddison 2009). However, the nature of the process is different than the spatial lag model implies. The premise of the spatial lag model is that the price of a property is affected by the prices of neighboring properties. Nonetheless, it cannot be influenced by the prices of properties that were sold afterwards or many years prior. To account for the temporal aspect of this relationship, we adopt the approach of Maddison (2009) and use the spatio-temporal weight matrix that for each property identifies properties sold in earlier periods. The resulting model becomes a Manski model with spatio-temporal lag:

$$
\begin{aligned}
& \mathbf{P}=\alpha+\rho \mathbf{Z P}+\mathbf{X}^{\prime} \boldsymbol{\beta}+\mathbf{W X}^{\prime} \boldsymbol{\theta}+\boldsymbol{\varepsilon} \\
& \boldsymbol{\varepsilon}=\lambda \mathbf{W} \boldsymbol{\varepsilon}+\mathbf{u}
\end{aligned}
$$

where $\mathbf{Z}$ is a $n \times n$ spatio-temoral and $\mathbf{W}$ is a $n \times n$ spatial weight matrices that define the way in which observational units are believed to be influencing each other, $\mathbf{Z P}$ is a spatio-temporal interaction effect, $\mathbf{W X}$ is an exogenous interaction effect, $\mathbf{W} \boldsymbol{\varepsilon}$ is an interaction effects between disturbance terms, $\rho$ is the spatio-temporal autoregressive (lag) coefficient, $\lambda$ is the spatial autocorrelation (error) coefficient, $\boldsymbol{\theta}$ is a vector of the parameters of exogenous interaction effects, and $\mathbf{u}$ is an uncorrelated error term, i.e. $\mathbf{u} \sim N\left(0, \sigma^{2}\right)$. Spatio-temoral weight matrix $\mathbf{Z}$ is calculated as $\mathbf{W} \circ \mathbf{T}$, where $\mathbf{T}$ is a matrix that for each property identifies properties sold in earlier periods. We assume that agricultural land values are affected by spatially weighted prices of properties sold in the preceding two years: 


$$
\mathbf{T}_{i j}= \begin{cases}1 & \text { if } 0<D_{i}-D_{j} \leq 2 \\ 0 & \text { otherwise }\end{cases}
$$

where $D_{i}$ and $D_{j}$ are sale dates (in years) of properties $i$ and $j$, respectively.

Using a spatio-temporal weight matrix removes simultaneity that exists in the estimation of the parameter of conventional spatial lag. On the other hand, the exogenous effects (effects of spatially lagged explanatory variables) as well as correlated effects (spatial error) are not affected by temporal issues because the sources of these effects are characteristics of neighboring properties, spatially correlated omitted variables, or measurement error in spatially correlated variables, which we assume do not change with time. Therefore, we use the spatial weight matrix $\mathbf{W}$ for spatial error and spatially lagged dependent variables. Furthermore, we do not spatially lag distance-based explanatory variables since they are characteristics of locations rather than characteristics of individual observations and are highly correlated with their spatial lags.

Imposition of restrictions on one or more spatial parameters of the model [2] yields other familiar spatial models (Elhorst 2010). For example, restricting $\boldsymbol{\theta}=0$ results in Kelejian-Prucha model (Kelejian and Prucha 1998), $\lambda=0$ results in spatial Durbin model, while $\boldsymbol{\theta}=0$ and $\rho=0$ yields spatial error model. While our specification is based on hypotheses about the presence of three spatial processes described earlier, we will test whether any of the spatial processes is present in the data by imposing restrictions on the spatial coefficients.

The choice of the weight matrix is important as it influences the model results. Depending on the nature of the spatial process, the weight matrix can be constructed 
using simple contiguity based-weights, n-nearest neighbor-based weights, or threshold distance-based weights (Anselin 1988). However, most observations in our data set are not immediate neighbors, so the threshold distance-based weight matrix is more plausible than the other options. Furthermore, there could be an assumption about weakening of the spatial relationship with distance, with the most common assumption being that it decays proportionally to the inverse distance between the observations. In this study, we adopt a threshold-based weight matrix with both threshold distance and weight derived from the observed data by analyzing a covariogram based on ordinary least squares (OLS) residuals (Polyakov et al. 2013). A covariogram is the covariance between pairs of residuals depending on lag (distance between the observations) $h$ :

$$
C(h)=\frac{1}{N(h)} \sum_{N(h)}\left(z\left(s_{i}\right)-\bar{z}\right)\left(z\left(s_{j}\right)-\bar{z}\right)
$$

where $C(h)$ is covariace at lag $h, N(h)$ is a number of observations with lag $h, z\left(s_{i}\right)$ is the value of a variable (residual in our case) at point $s_{i}$. There are several theoretical models that could be fitted to the empirical covariogram, the most common being exponential (5), Gaussian (6), and spherical (7) (Tu, Sun and Yu 2007):

$$
\begin{aligned}
& C(h)=c_{0} \times \exp (-h / r) \\
& C(h)=c_{0} \times \exp \left(-(h / r)^{2}\right) \\
& C(h)= \begin{cases}c_{0}\left[1-\frac{3}{2}(h / r)-\frac{1}{2}(h / r)^{3}\right] & \text { if } h \leq r \\
0 & \text { if } h>r\end{cases}
\end{aligned}
$$


where $c_{0}$ and $r$ are, respectively, "scale" and "range" parameters to be estimated. The appropriate theoretical model is selected using a goodness-of-fit measure. To determine the threshold distance of the spatial weight matrix, the effective range $\left(r_{e}\right)$ of the covariogram is used. The effective range is the distance where the covariogram falls to 5 per cent of its maximum value. It is expressed differently depending on the type of covariogram: for the exponential covariogram $r_{e}=3 r$, for the Gaussian covariogram $r_{e}=\sqrt{3} r$, and for the spherical covariogram $r_{e}=r$.

Another approach to control omitted variable bias and spatial dependence caused by unobservable spatially correlated variables is the use of spatial fixed effects. In crosssection settings, spatial fixed effects are the indicator variables shared by all observations belonging to spatial units such as census blocks, census statistical areas, school districts, or local government areas. Spatial fixed effects can remove spatial correlation where unobservable variables are associated with well-delineated groups such as school districts (Anselin and Arribas-Bel 2013; Kuminoff, Parmeter and Pope 2010). Therefore, in addition to estimating the Manski model with spatio-temporal lag, we also estimate a spatial fixed effect model.

\section{Study area, data, and variables}

This study seeks to estimate the value of native woody vegetation on private properties in agriculture-dominated landscapes of north-central Victoria, Australia. The study area (figure 1) is a three million ha region within which the North Central Catchment Management Authority (CMA) plays an important role in coordinating and implementing a range of environmental projects. The region is bordered by the Murray River to the 
north, the Great Dividing Range to the south, and Mt Camel Range to the east. The elevation of the study area ranges from $50 \mathrm{~m}$ above sea level in the north-west to $1000 \mathrm{~m}$ above sea level in the south-east, with annual precipitation following a similar gradient ranging from $350 \mathrm{~mm}$ in the north-west to $1350 \mathrm{~mm}$ in the south-east. There are four major river systems in the region: the Campaspe, the Loddon, the Avoca, and the AvonRichardson. The first three run into the Murray River, while the fourth ends in a series of terminal lakes. Approximately $17 \%$ of the region is covered by native woody vegetation; the rest was cleared for extensive agriculture in the late $19^{\text {th }}$ and early $20^{\text {th }}$ centuries. About $13 \%$ of the region is public land, including national, state and regional parks. The region has significant areas of irrigated and dry-land agriculture, with some horticulture and lifestyle farming in proximity to major population centers. According to the 2011 Census, the population of the area is 223,348 people with the majority concentrated in larger towns, including Bendigo, Castlemaine, Maryborough, Echuca and Swan Hill.

[Insert Figure 1 about here]

We acquired property sales data from the Valuer General's Office of the State of Victoria. The sales records contain information on sale price, sale date, land area, land use, and Standard Parcel Identifiers of the property parcels. These Identifiers were used to combine sales records with the state cadastral parcel layer obtained from North Central CMA. We used properties sold between 1990 and 2011 that were classified as lifestyle, cropping, grazing, and mixed farming properties with areas greater than 1 ha and located in rural land uses (agricultural, nature protection, or rural residential). We discarded observations where land area recorded in the database deviates from the area calculated 
by GIS by more than $10 \%$. For the properties that were sold multiple times, we retained only the latest sale record. We plotted $\log ($ price per hectare) against $\log ($ area $)$, inspected the plot, and removed obvious outliers. This resulted in 7598 observations. We set aside observations prior to 1992 to construct the spatio-temporal lag and the remaining 7205 observations were used in the final analysis.

The TREEDEN25 GIS dataset developed by Victorian Department of Sustainability and Environment was used to calculate the proportion of native woody vegetation on each property. This dataset is based on 1999 SPOT panchromatic imagery with $10 \mathrm{~m}$ pixels. It identifies woody vegetation greater than 2 meters in height and with a crown cover greater than 10 percent. Controls on landholders clearing native vegetation were established in 1986, after which clearing was only permitted for a limited range of purposes, such as residential development. Kyle and Duncan (2012) have found that there was very little change of native woody vegetation cover in North Central Victoria during 1991-2008. Therefore we assume that there would have been no major loss of vegetation from the early 1990 s to the present and TREEDEN25 provides an accurate representation of the extent of native vegetation on rural properties during the study period. The dominant landforms of the properties were identified using the Victoria Land Systems dataset (Rees and Rowan 2000). The slope of the properties was calculated using a 90meter-resolution Digital Elevation Model (Jarvis et al. 2008). From the website of the Australian Bureau of Meteorology we obtained $2.5 \mathrm{~km}$ resolution average annual rainfall data. 
Descriptive statistics of the model variables are presented in table 1 . The dependent variable is per-hectare sale price of rural property deflated using the Consumer Price Index obtained from the Australian Bureau of Statistics. The natural log of property area is included in the model to control for the fact that larger properties have a lower per-hectare price. Many properties have houses and other structures; however, only data regarding the number of bedrooms is available. Following Maddison (2009), we divided the number of bedrooms by area in hectares to represent the level of structural attributes per unit of land.

[Insert Table 1 about here]

Ecosystem services related to agricultural production were accounted for by including variables describing slope, landform, precipitation, distance to the river, and irrigation district. Landform characteristics are represented by binary variables "plain" and "floodplain", with "mountain/hill/low hill/rise" being the reference landform. Some of these landforms might affect recreational and aesthetic amenity values; for example, a property located on a "plain" is expected to have higher agricultural production value while it is expected to have lower amenity value. We expect that proximity to the river or creek has a positive effect on both production and amenity values. A binary variable "irrigated" indicates that the property is located in the irrigation zone, which is beneficial for agricultural production.

The variables related to environmental assets that provide cultural, recreational, and aesthetic amenity values to the landowners are landform, slope, proximity to river or creek, proximity to the nearest national, state or regional park, and native woody 
vegetation on the property. We expect that hilly terrain and steeper slopes, as well as proximity to river, creek, or park, increase the amenity value of a property.

Consider $a$ hectares of rural property allocated to a combination of two alternative land uses: $a_{n v}$ is the area of native vegetation and $a-a_{n v}$ is the area of agricultural land use. Let $V_{n v}\left(a_{n v}\right)$ be value of native vegetation and $V_{a g}\left(a-a_{n v}\right)$ be value of land in agricultural use (figure $2 \mathrm{a}$ ). We assume that each of the land uses has positive diminishing marginal value (figure $2 \mathrm{~b}$ ). The value of a property of $a$ hectares with $a_{n v}$ ha of native vegetation $V\left(a_{n v} \mid a\right)$ follows an inverted "U" shape (figure 2 a). The value of a property reaches a maximum at $a_{n v}^{*}$ where marginal value of native vegetation is equal to the marginal value of agricultural land. We expect that the decline of marginal value of native vegetation is steeper than that of agricultural land, so for larger properties maximal value occurs at lower proportions of native vegetation and a large area of native vegetation has a greater negative impact on the values of these properties. Because we use value of the property per hectare as a dependent variable, we model the effect of two competing land uses by including in the model linear and quadratic terms for the proportion of native vegetation and the interaction of the proportion of native vegetation with the natural log of property area.

[Insert Figure 2 about here]

To control for accessibility to markets, services, employment, and other urbanbased amenities, which are important for both hobby farmers and production-oriented landowners, we use two variables: distance to the nearest major road and a Population 
Gravity Index (PGI) (Polyakov, Majumdar and Teeter 2008). The PGI is calculated as the sum of the inverse squared distance weighted population of urban centers and localities within a certain radius from the property. It accounts for the combined influence of the size and proximity of populated places. We include urban centers and localities within a $700 \mathrm{~km}$ radius of the property to account for the influence of three major metropolitan areas: Sydney, Melbourne and Adelaide. To control for the annual growth of property prices, we included a continuous trend variable that indicates year of sale since January 1, 1990 (for example, the value of trend variable for the property sold on March 18, 1996 is $6.21)$.

\section{Results and Discussion}

To determine the functional form for the hedonic model of rural land prices (4), we used the Box-Cox test. The test indicated that the hedonic price function with a natural-logtransformed dependent variable is the most appropriate functional form. To improve goodness of fit of the model, we use log-transformed property area and distance-based explanatory variables.

We hypothesize that some factors used in the model could have different effects across the range of property sizes. The rationale for this hypothesis is that there is variation among landholders in their reasons for owning a property and thus there will be differences in the importance of production versus amenity values. Smaller properties are usually associated with hobby farmers, for whom cultural, recreational, and aesthetic amenity values are relatively important, while larger properties are usually associated with full-time commercial farmers, who value the agricultural productivity of the land. 
This could imply that the rural property market is segmented. First, we test this hypothesis by interacting explanatory variables with a "Lifestyle" dummy variable taking the value of 1 for properties smaller than 20 ha, which is a definition of lifestyle properties. F-test $\left(F_{13,7177}=50.0, p<2.2 \mathrm{e}-16\right)$ indicated that there are structural differences between lifestyle properties and larger properties. However, the continuum of property types and sizes is not sharply split. For example, medium-sized properties are associated with part-time farmers who pursue a combination of production and lifestyle goals. In order to account for possible gradual shifts in the combination of landowner's goals and preferences, we interacted all explanatory variables with the natural log of property area. This model supports the hypothesis of the existence of a gradual structural shift in parameters along the range of property sizes $\left(F_{13,7177}=70.5, p<2.2 \mathrm{e}-16\right)$ and it has a better fit than the model where explanatory variables are interacted with a "Lifestyle" dummy variable ( $\mathrm{R}^{2}$ of basic model, model with "lifestyle dummies and model with $\log ($ area $)$ are $0.849,0.862$ and 0.866 , respectively). Therefore, we select the model where explanatory variables are interacted with the log of property area to represent structural shift in the explanatory variables along the gradient of property sizes. The model explains $85 \%$ of the variation of the per-hectare property value. The spatially explicit and cross-sectional property sales data often result in heteroskedasticity and spatial autocorrelation (Boxall, Chan and McMillan 2005; Wasson et al. 2013). A Breusch-Pagan test rejects the null hypothesis of homoskedasticity in the model at $1 \%$ significance level. 
In order to test for spatial autocorrelation we need to construct a spatial weight matrix. To determine threshold distances and the spatial relationship decay function of the spatial weight matrix, we estimated an empirical covariogram of the OLS model residuals (1). Results of the nonlinear least squares estimation of the theoretical exponential (5), Gaussian (6), and spherical (7) covariogram models are presented in table 2. Empirical and theoretical covariograms are shown in figure 3. Regression results and the graphs suggest that the exponential covariogram fits the data best. Examination of the graphs confirms that spatial dependence in the model diminishes at an effective range distance of about $25 \mathrm{~km}$.

[Insert Table 2 about here]

[Insert Figure 3 about here]

We constructed the row-normalized spatial weight matrix $\mathbf{W}$ using a threshold distance of 25 kilometers and the weights of the individual elements proportional to the covariance predicted using exponential covariogram (5). The row-normalized spatiotemporal weight matrix $\mathbf{Z}$ was constructed using the same threshold distance and weight function by including only observations in the 730 days preceding the sale of each property. The weight matrix $\mathbf{W}$ was used to test the OLS model for autocorrelation. Results of the test are presented in table 3. The Moran's I value indicates a clustering pattern of the residuals. Both the Lagrange multiplier and Robust Lagrange multiplier tests (Anselin et al. 1996) indicate the presence of spatial error and spatial lag dependencies; however, spatial error dependency is much more prominent. The presence of heteroskedasticity can affect the validity of Moran's I and the Lagrange Multiplier in 
testing for spatial autocorrelation (Anselin and Rey 1991). Therefore we use the test devised by Kelejian and Robinson (1992), which confirms the presence of spatial autocorrelation (table 3).

[Insert Table 3 about here]

To control spatial autocorrelation which might be a result of omitted spatially correlated variables, we first estimate a spatial fixed effect model (Kuminoff, Parmeter and Pope 2010). We use Statistical Areas Level 1 (SA1) as spatial fixed effects. Under the Australian Statistical Geography Standard (ASGS), the SA1 is the smallest unit for the release of Census data, and has a population of 200 to 800 persons with an average population of about 400 persons. For these fixed effects to be usable, we merge SA1s that contain less than 10 observations with the nearest SA1. The number of observations in amended SA1s varies between 11 and 129 with median 38 .

Estimation results of the spatial fixed effects model and the Manski model with spatio-temporal lag (2) are presented in table 4. Due to the presence of heteroskedasticity in both models, we estimate and report robust standard errors. Spatial error and spatiotemporal lag coefficients are positive and significant, confirming the presence of positive spatial relationships. Figure 4 shows a map of spatial fixed effects of the spatial fixed effect model and a map of the spatially correlated part of error of the Manski model with spatio-temporal lag. Spatial fixed effects and spatially correlated errors show a similar pattern. However, spatial fixed effects are confined to somewhat arbitrary spatial units (SA1 in this case), while the pattern of spatially correlated errors is more flexible and potentially can accommodate spatially correlated unobservables that are related to 
environmental factors that are not related to chosen spatial units. We test whether each of the spatial effects belongs to the model by imposing restrictions on spatial parameters of the spatio-temporal lag, spatial error, and spatially lagged explanatory variables. The likelihood ratio test rejects the hypotheses that $\rho=0\left(\chi_{1}^{2}=80.7 p=2.7 \mathrm{E}-19\right)$, that $\lambda=0$ ( $\left.\chi_{1}^{2}=221.4 p<4.4 \mathrm{E}-50\right)$, and that $\boldsymbol{\theta}=0\left(\chi_{8}^{2}=13.7, p=8.9 \mathrm{E}-02\right)$. Furthermore, the spatial model outperforms the spatial fixed effect model (AIC 12585 and 12632, respectively). Therefore, we conclude that the Manski model with spatio-temporal lag (3) is the appropriate model and in the rest of the article we discuss coefficients estimated using this model.

[Insert Table 4 about here]

[Insert Figure 4 about here]

Most of the coefficient estimates of the spatial model are statistically significant and have signs that are consistent with the signs of the spatial fixed effects model estimates. The significance of the coefficients of the variables interacted with the natural $\log$ of property area indicates that there are structural shifts along the range of property sizes for most of the factors determining the price of rural properties, and in many cases the effects are opposite at the different ends of the property size range.

The coefficient estimate for the log of property area is negative and highly significant, which is consistent with most other studies of rural land values that use perunit area price as the dependent variable (Chicoine 1981; Huang et al. 2006; Ma and Swinton 2011; Maddison 2009). It implies that per-hectare value is decreasing with property size reflecting declining marginal benefits, which may be caused by subdivision 
costs, lower liquidity of larger properties, and asymmetric information (Chicoine 1981). Furthermore, the positive coefficient for the squared term of log area indicates that the marginal return is decreasing at a decreasing rate. The coefficient estimate for bedrooms per hectare is positive and significant, as expected, indicating that a house adds value to the property. The coefficient for the interaction effect of the number of bedrooms with property area indicates that the presence of a house has a greater effect on larger properties.

The estimate of the coefficient for average annual precipitation is negative, while the coefficient estimate of its interaction with log property area is positive. This means that precipitation has a negative effect on the values of smaller properties (less than approximately 5 ha in size) but a positive effect on the value of properties larger than 5 ha, with the positive effect increasing with property size. For example, an additional 10 $\mathrm{mm}$ of average precipitation per year increases the value of a 500 ha property by about $1.8 \%$. We expected that precipitation would be important for larger properties because it is a limiting factor in agricultural production. The negative effect for smaller properties is significant at $5 \%$ level only for properties smaller than 2 ha.

Location on a steeper slope does not have a significant effect on the value of smaller properties; however, it lowers the value of larger properties, as indicated by the negative coefficient of this variable that is interacted with log area. The reason is that steeper slopes are impediments to agricultural production, which is more important for the owners of larger properties. Hilly terrain might be a source of visual amenities which are relatively more important for the owners of smaller properties. This is supported by 
the coefficient of the "plain" dummy variable and its interaction with property size, which indicates that location on the plain increases the value of large properties, where agricultural production is more important than amenity value. Location on a floodplain positively affects property values regardless of property size. The value of location within the irrigation district is positive, and more so as the size of the property increases because this factor is important for agricultural production. Proximity to rivers or creeks increases property value, which is consistent with results reported by Ma and Swinton (2011). The coefficient of the interaction term between log of the distance to the river and log of the property area shows that the positive effect of proximity to rivers or creeks is similar for large and small properties. The distance to the nearest national, state, or regional park does not have a significant effect on property values. This could be because most parks are located on rise, hill or mountain landforms, and the effect of landform is already incorporated into the model.

The population gravity index, a measure of population and market access, positively influences rural property values. Proximity to populated places drives demand for smaller properties, such as residential, lifestyle, and hobby farms (Bastian et al. 2002; Polyakov et al. 2013; Sengupta and Osgood 2003), while proximity to markets is important for larger, agricultural-production-oriented properties. The influence of the population gravity index increases with property size. This might indicate that values of agricultural properties in close proximity to populated places are also driven by speculative expectations of possible development or conversion to residential properties or a hobby farms (Wear and Newman 2004). Proximity to major roads increases the 
value of smaller properties and has a negative effect on the value of larger properties. The trend variable indicates an increase in the inflation-adjusted property value over time, which is not surprising. The interaction between trend and log area variables shows that the annual rate of increase in property value is different for properties of different sizes. Specifically, for a 1000 ha property the rate of increase is barely $0.6 \%$ per year, for a 100 ha property it is $3.0 \%$, for a 10 ha property it is $5.5 \%$, and for a 1 ha property the annual rate of increase is $8.0 \%$.

The proportion of native woody vegetation on the property has a statistically significant, positive and diminishing marginal impact on property values as indicated by the coefficients of the linear and quadratic terms of this variable, consistent with the findings of Polyakov et al. (2013). In addition, we find that the effect diminishes with property size as the goals of ownership shift from lifestyle to production and the importance of amenity values decreases. This is consistent with the findings of Race et al. (2010) that part-time and hobby farmers undertake a substantially greater amount of work to re-vegetate and enhance native vegetation than full-time production-oriented farmers. Similarly, Adams (2011) found that the probability of landholders' participation in conservation programs decreases with property size and with the increase in proportion of property required for conservation management.

The effect of native woody vegetation on the per-hectare value of rural land by property size is shown on the figure 5. It shows that the marginal effect of native vegetation on per-hectare value is diminishing for all property sizes, but for larger properties the positive effect is smaller and becomes negative faster as the proportion of 
native vegetation increases. The optimal proportions of native woody vegetation for a 10 ha, 100 ha, and 1000 ha property are estimated to be $37 \%, 29 \%$, and $20 \%$, respectively. These proportions would increase property values by $16 \%, 9 \%$, and $5 \%$ relative to the values of similar properties without any native vegetation. Optimal proportions of native vegetation are higher than the median observed proportions across the range of property sizes suggesting that some re-vegetation would be beneficial to a majority of landholders.

[Insert Figure 5 about here]

Findings from this study can be used in a variety of ways to improve environmental management in the region. Firstly, it can contribute to decisions about which farmers should be targets for public programs. Investments in farmers with relatively high marginal private benefits from revegetation would be more likely to provide high value for money, because they are likely to be willing to participate in a revegetation program at lower public cost (although other factors, such as the public environmental benefits, will also need to be considered). For example, the map in figure 6 presents the increase in the proportion of native vegetation that would maximize property value (therefore maximizing benefit to property owners). It could be used by extension professionals and natural resource managers as a decision support tool for targeting ecological restoration on private properties.

[Insert Figure 6 about here]

Secondly, information about the private value of native vegetation can improve the quality of results from models that optimize the spatial allocation of ecological restoration (e.g., Polyakov et al. 2011; Westphal, Field and Possingham 2007). Typically 
these models account weakly or not at all for private benefits of restoration, resulting in sub-optimal solutions.

Thirdly, these results may be used as inputs to cost-benefit analyses of projects to encourage re-vegetation. Cost-benefit analysis has been extensively used by the regional environmental management body responsible for most of the study region (Pannell et al. 2012).

Fourthly, the findings will help with the selection of efficient policy mechanisms to encourage re-vegetation using the public-private benefits framework of Pannell (2008). He showed that optimal policy mechanism choice can be highly sensitive to the private benefits of the practices being promoted by a program.

Finally, the information about private values of ecological assets will contribute to judgments about the likely level of adoption of ecological restoration activities on private land, allowing managers to assess whether adoption is likely to be sufficient to justify investing the transaction costs in a project (Pannell et al. 2006).

\section{Conclusions}

In this study, we use property sales data for north-central Victoria, Australia, to estimate the capitalized value of private benefits generated by environmental assets using a spatio-temporal hedonic model. Specifically, we focus on native woody vegetation on rural properties in a region where landholders have a wide range of management goals. Native woody vegetation generates both private and public benefits, but this study focuses on the estimation of private benefits. 
We employ a data-driven approach to construct the spatial weight matrix and control simultaneously for spatio-temporal lag dependence, spatial exogenous lag dependence, and spatial error dependence present in the data. This allows us to effectively control for spatially correlated unobservables that are not confounded to spatial units such as census statistical areas and as a result we obtain unbiased and efficient estimates of the model parameters. Ignoring spatial dependencies would result in biases in estimates of the coefficients of spatially correlated variables such as precipitation and slope, as well as distance-based variables, such as proximity to the river or population gravity index.

This study contributes to the existing literature in the following ways. Firstly, we find that native woody vegetation provides amenity benefits to the landowners; however, its marginal value diminishes as the proportion of native vegetation on the property increases. Secondly, we use a novel approach to model structural shifts in the impacts of most factors determining property values in a heterogeneous property market. These shifts occur along the range of property sizes, which are associated with the mix of landowners' land-use objectives (for example full-time farmers, part-time farmers, or lifestyle landowners). Thirdly, we find that the marginal value of native vegetation is smaller on larger properties, which are associated with production-oriented farmers, and larger on smaller properties, which are associated with lifestyle landowners.

The current extent of native vegetation is lower than the extent that would maximize its amenity value to many landowners, indicating that there may be scope to enhance the welfare of people living in this area by restoring native vegetation on cleared 
lands. Of course, the merits of this proposition depend on the costs of restoration and the time lag between the cost of restoration and the benefits.

Our results contribute to an active policy debate in Australia about the need for improved targeting of public environmental investments. Most existing programs provide the same level of financial support to all participants, irrespective of their private benefits (or costs). We demonstrate that there is high heterogeneity in the private benefits of native vegetation. As such, there is scope for improved targeting of investment in the study region by incorporating private benefits of environmental projects. Landowners with high marginal private benefits from revegetation would be more willing to participate in a revegetation program. Targeting those landowners would likely to provide higher value for money, because such projects could be implemented at lower public cost. 


\section{References}

Adams, V.M. 2011. "Incorporating Socio-Economic Considerations into Systematic Conservation Planning " PhD thesis, James Cook University.

Anselin, L. 1988. Spatial Econometrics: Methods and Models. Dordrecht: Kluwer Academic Publishers.

Anselin, L., and D. Arribas-Bel. 2013. "Spatial Fixed Effects and Spatial Dependence in a Single Cross-Section." Papers in Regional Science 92:3-17.

Anselin, L., A.K. Bera, R. Florax, and M.J. Yoon. 1996. "Simple Diagnostic Tests for Spatial Dependence." Regional Science and Urban Economics 26:77-104.

Anselin, L., and S. Rey. 1991. "Properties of Tests for Spatial Dependence in Linear Regression Models." Geographical Analysis 23:112-131.

Australian National Biodiversity Strategy Review Task Group. 2010. Australia's Biodiversity Conservation Strategy 2010-2030 / Prepared by the National Biodiversity Strategy Review Task Group Convened under the Natural Resource Management Ministerial Council. Canberra: Dept. of Sustainability, Environment, Water, Population and Communities.

Bastian, C.T., D.M. McLeod, M.J. Germino, W.A. Reiners, and B.J. Blasko. 2002. "Environmental Amenities and Agricultural Land Values: A Hedonic Model Using Geographic Information Systems Data." Ecological Economics 40:337349. 
Blackmore, L., and G.J. Doole. 2013. "Drivers of Landholder Participation in Tender Programs for Australian Biodiversity Conservation." Environmental Science and Policy 33:143-153.

Boxall, P.C., W.H. Chan, and M.L. McMillan. 2005. "The Impact of Oil and Natural Gas Facilities on Rural Residential Property Values: A Spatial Hedonic Analysis." Resource and Energy Economics 27:248-269.

Chicoine, D.L. 1981. "Farmland Values at the Urban Fringe: An Analysis of Sale Prices." Land Economics 57:353-362.

DSE. 2009. Securing Our Natural Future: A White Paper for Land and Biodiversity at a Time of Climate Change. Melbourne, Victoria, Australia: Victorian Government Department of Sustainability and Environment.

Elhorst, J.P. 2010. "Applied Spatial Econometrics: Raising the Bar." Relever le niveau de l'économetrie spatial appliquée 5:9-28.

Hajkowicz, S. 2009. "The Evolution of Australia's Natural Resource Management Programs: Towards Improved Targeting and Evaluation of Investments." Land Use Policy 26:471-478.

Huang, H., G.Y. Miller, B.J. Sherrick, and M.I. Gómez. 2006. "Factors Influencing Illinois Farmland Values." American Journal of Agricultural Economics 88:458470.

Jarvis, A., H.I. Reuter, A. Nelson, and E. Guevara (2008) "Hole-Filled Srtm for the Globe Version 4, Available from the Cgiar-Csi Srtm 90m Database " In. 
Kelejian, H.H., and I.R. Prucha. 1998. "A Generalized Spatial Two-Stage Least Squares Procedure for Estimating a Spatial Autoregressive Model with Autoregressive Disturbances." Journal of Real Estate Finance and Economics 17:99-121.

Kelejian, H.H., and D.P. Robinson. 1992. "Spatial Autocorrelation. A New Computationally Simple Test with an Application to Per Capita County Police Expenditures." Regional Science and Urban Economics 22:317-331.

Kuminoff, N.V., C.F. Parmeter, and J.C. Pope. 2010. "Which Hedonic Models Can We Trust to Recover the Marginal Willingness to Pay for Environmental Amenities?" Journal of Environmental Economics and Management 60:145-160.

Kyle, G., and D.H. Duncan. 2012. "Arresting the Rate of Land Clearing: Change in Woody Native Vegetation Cover in a Changing Agricultural Landscape." Landscape and Urban Planning 106:165-173.

Ma, S., and S.M. Swinton. 2011. "Valuation of Ecosystem Services from Rural Landscapes Using Agricultural Land Prices." Ecological Economics 70:16491659.

Maddison, D. 2009. "A Spatio-Temporal Model of Farmland Values." Journal of Agricultural Economics 60:171-189.

Manski, C.F. 1993. "Identification of Endogenous Social Effects - the Reflection Problem." Review of Economic Studies 60:531-542.

Nagelkerke, N.J.D. 1991. "A Note on a General Definition of the Coefficient of Determination." Biometrika 78:691-692. 
Olsen, P., M. Weston, C. Tzaros, and A. Silcocks. 2005. The State of Australia's Birds 2005. Melbourne: Birds Australia.

Pannell, D.J. 2008. "Public Benefits, Private Benefits, and Policy Mechanism Choice for Land-Use Change for Environmental Benefits." Land Economics 84:225-240. Pannell, D.J., G.R. Marshall, N. Barr, A. Curtis, F. Vanclay, and R. Wilkinson. 2006. "Understanding and Promoting Adoption of Conservation Practices by Rural Landholders." Australian Journal of Experimental Agriculture 46:1407-1424.

Pannell, D.J., A.M. Roberts, G. Park, J. Alexander, A. Curatolo, and S.P. Marsh. 2012. "Integrated Assessment of Public Investment in Land-Use Change to Protect Environmental Assets in Australia." Land Use Policy 29:377-387.

Polyakov, M., I. Majumdar, and L. Teeter. 2008. "Spatial and Temporal Analysis of the Anthropogenic Effects on Local Diversity of Forest Trees." Forest Ecology and Management 255:1379-1387.

Polyakov, M., D.J. Pannell, R. Pandit, S. Tapsuwan, and G. Park. 2013. "Valuing Environmental Assets on Rural Lifestyle Properties." Agricultural and Resource Economics Review 42:159-175.

Polyakov, M., D.J. Pannell, A.D. Rowles, G. Park, and A. Roberts. 2011. "Optimising the Spatial Pattern of Landscape Revegetation." Paper presented at Australian Agricultural and Resource Economics Society Conference. Melbourne, Victoria. Race, D., R. Sample, A. Curtis, and S. McDonald. 2010. Management of Native Vegetation on Private Land: Perspectives of Landholders and Nrm Program Managers in Northern Victoria: Landscape Logic. 
Raymond, C.M., and G. Brown. 2011. "Assessing Conservation Opportunity on Private Land: Socio-Economic, Behavioral, and Spatial Dimensions." Journal of Environmental Management 92:2513-2523.

Rees, D.B., and J. Rowan. 2000. Land Systems of Victoria. Epsom, Vic.: Victoria Dept. of Natural, Resources and Environment, Centre for Land Protection and Research.

Rosen, S. 1974. "Hedonic Prices and Implicit Markets - Product Differentiation in Pure Competition." Journal of Political Economy 82:34-55.

Sengupta, S., and D.E. Osgood. 2003. "The Value of Remoteness: A Hedonic Estimation of Ranchette Prices." Ecological Economics 44:91-103.

Thomson, J.R., A.J. Moilanen, P.A. Vesk, A.F. Bennett, and R. Mac Nally. 2009. "Where and When to Revegetate: A Quantitative Method for Scheduling Landscape Reconstruction." Ecological Applications 19:817-828.

Torell, L.A., N.R. Rimbey, O.A. Ramírez, and D.W. McCollum. 2005. "Income Earning Potential Versus Consumptive Amenities in Determining Ranchland Values." Journal of Agricultural and Resource Economics 30:537-560.

Tu, Y., H. Sun, and S.M. Yu. 2007. "Spatial Autocorrelations and Urban Housing Market Segmentation." Journal of Real Estate Finance and Economics 34:385-406.

Walpole, S.C., and M. Lockwood. 1999. "Influence of Remnant Native Vegetation on Rural Land Values: A Hedonic Pricing Application." Paper presented at The Australian and New Zealand Agricultural and Resource Societies 1999 Joint Conference. Christchurch, New Zealand. 
Wasson, J.R., D.M. McLeod, C.T. Bastian, and B.S. Rashford. 2013. "The Effects of Environmental Amenities on Agricultural Land Values." Land Economics 89:466478.

Wear, D.N., and D.H. Newman. 2004. "The Speculative Shadow over Timberland Values in the Us South." Journal of Forestry 102:25-31.

Westphal, M.I., S.A. Field, and H.P. Possingham. 2007. "Optimizing Landscape Configuration: A Case Study of Woodland Birds in the Mount Lofty Ranges, South Australia." Landscape and Urban Planning 81:56-66. 


\section{Tables}

Table 1. Descriptive Statistics of the Variables

\begin{tabular}{|c|c|c|c|c|c|}
\hline Variable & Mean & St dev. & Min. & Median & Max. \\
\hline Adjusted price $\$ /$ ha & 40,750 & 70,145 & 145 & 13,217 & 870,707 \\
\hline Area, ha & 43.1 & 73.1 & 1.0 & 12.2 & 1078.9 \\
\hline Bedrooms per ha & 0.34 & 0.63 & 0.00 & 0.00 & 3.99 \\
\hline Plain & 0.48 & 0.50 & 0 & 0 & 1 \\
\hline Floodplain & 0.05 & 0.22 & 0 & 0 & 1 \\
\hline Irrigated & 0.21 & 0.40 & 0 & 0 & 1 \\
\hline Slope, degrees & 1.88 & 1.70 & 0.00 & 1.37 & 17.38 \\
\hline Precipitation, $\mathrm{m}$ & 0.575 & 0.186 & 0.343 & 0.530 & 1.361 \\
\hline Proportion of native vegetation & 0.21 & 0.28 & 0.00 & 0.08 & 1.00 \\
\hline \multicolumn{6}{|l|}{ on the property } \\
\hline Distance to national, atate or & 14.72 & 14.79 & 0.00 & 10.63 & 74.53 \\
\hline \multicolumn{6}{|l|}{ regional park, km } \\
\hline Distance to the main road, $\mathrm{km}$ & 5.5 & 5.3 & 0.0 & 3.9 & 30.1 \\
\hline Distance to the river, $\mathrm{km}$ & 2.9 & 3.3 & 0.0 & 1.8 & 23.8 \\
\hline PGI & 1056 & 1009 & 166 & 903 & 25351 \\
\hline Trend, years & 12.8 & 5.7 & 2.0 & 14.3 & 21.5 \\
\hline
\end{tabular}


Table 2. Results of Nonlinear Least Squares Fitting Empirical Covariogram

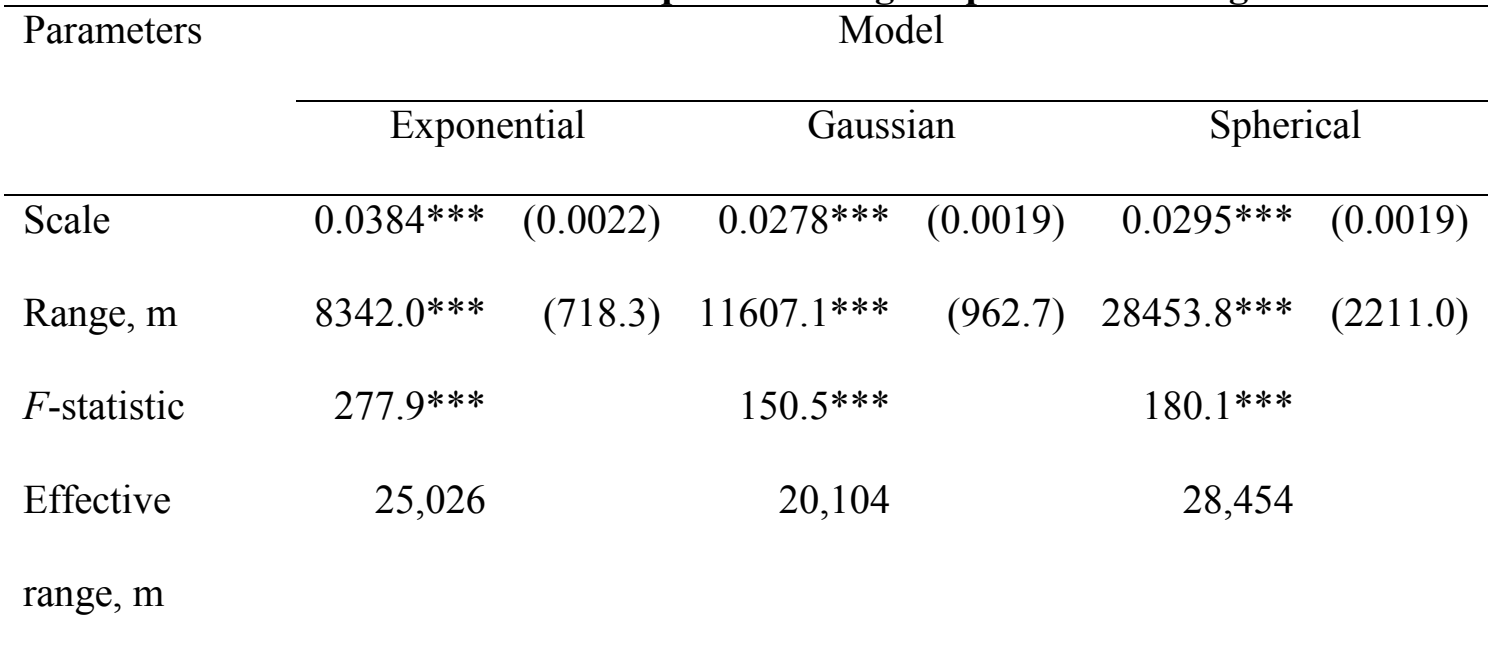

Note: standard errors are in parentheses.

*** significant at $1 \%$ level. 
Table 3. Tests of Spatial Autocorrelation in the OLS Model

Test Test value P-value

Spatial correlation in OLS residuals

Moran's $I$ statistics standard deviate

$43.9<2.2 \mathrm{e}-16$

Spatial error dependence

Lagrange multiplier test

$1850.9<2.2 \mathrm{e}-16$

Robust Lagrange multiplier test

$1711.8<2.2 \mathrm{e}-16$

Kelejian-Robinson test

$3519.8<2.2 \mathrm{e}-16$

Spatial lag dependence

Lagrange multiplier test

$218.1<2.2 \mathrm{e}-16$

Robust Lagrange multiplier test

$79.0<2.2 \mathrm{e}-16$

Spatial lag and error dependance (SARMA)

Lagrange multiplier test

$1929.9<2.2 \mathrm{e}-16$ 
Table 4. Regression Results

\begin{tabular}{|c|c|c|c|c|c|c|}
\hline \multirow{3}{*}{$\begin{array}{l}\text { Variable Name } \\
\text { Intercept }\end{array}$} & \multirow{2}{*}{\multicolumn{2}{|c|}{$\frac{\text { SFEM }}{\mathbf{X}}$}} & \multicolumn{4}{|c|}{ Manski model with spatio-temporal lag } \\
\hline & & & \multicolumn{2}{|c|}{$\mathbf{X}$} & \multicolumn{2}{|c|}{ WX } \\
\hline & $10.280 * * *$ & $(0.346)$ & $7.790 * * *$ & $(0.447)$ & & \\
\hline $\log ($ Area $)$ & $-1.307 * * *$ & $(0.099)$ & $-1.376^{* * *}$ & $(0.097)$ & 0.051 & $(0.079)$ \\
\hline $\log ($ Area $)$ squared & $0.062 * * *$ & $(0.005)$ & $0.063 * * *$ & $(0.005)$ & & \\
\hline Bedrooms per ha & $0.071 * * *$ & $(0.020)$ & $0.074 * * *$ & $(0.020)$ & 0.190 & $(0.201)$ \\
\hline Bedrooms per ha $\times \log ($ Area $)$ & $0.530 * * *$ & $(0.021)$ & $0.504 * * *$ & $(0.021)$ & & \\
\hline Plain & -0.012 & $(0.042)$ & -0.017 & $(0.040)$ & $0.303 *$ & $(0.182)$ \\
\hline Plain $\times \log ($ Area $)$ & $0.035 * *$ & $(0.014)$ & $0.031 * *$ & $(0.014)$ & & \\
\hline Floodplain & $0.305 * * *$ & $(0.092)$ & $0.255^{* * *}$ & $(0.091)$ & $0.624 * *$ & $(0.296)$ \\
\hline Floodplain $\times \log ($ Area $)$ & -0.023 & $(0.029)$ & -0.024 & $(0.028)$ & & \\
\hline Irrigated & $0.167 * *$ & $(0.070)$ & 0.109 & $(0.070)$ & 0.191 & $(0.164)$ \\
\hline Irrigated × $\log ($ Area $)$ & 0.025 & $(0.016)$ & 0.025 & $(0.016)$ & & \\
\hline Slope & 0.011 & $(0.011)$ & 0.015 & $(0.011)$ & 0.066 & $(0.055)$ \\
\hline Slope $\times \log ($ Area $)$ & $-0.011 * *$ & $(0.004)$ & $-0.011 * * *$ & $(0.004)$ & & \\
\hline Precipitation & $-0.686 * * *$ & $(0.195)$ & $-0.533 * * *$ & $(0.196)$ & 0.565 & $(0.420)$ \\
\hline Precipitation $\times \log ($ Area $)$ & $0.347 * * *$ & $(0.048)$ & $0.357 * * *$ & $(0.047)$ & & \\
\hline $\begin{array}{l}\text { Proportion of tree cover on the } \\
\text { property }\end{array}$ & $0.953 * * *$ & $(0.112)$ & $1.026 * * *$ & $(0.109)$ & 0.093 & $(0.319)$ \\
\hline $\begin{array}{l}\text { Proportion of tree cover on the } \\
\text { property squared }\end{array}$ & $-1.028 * * *$ & $(0.102)$ & $-1.112 * * *$ & $(0.100)$ & & \\
\hline Proportion of tree cover $\times \log ($ Area $)$ & $-0.082 * * *$ & $(0.027)$ & $-0.083 * * *$ & $(0.026)$ & & \\
\hline $\begin{array}{l}\log (\text { Distance to national, state, or } \\
\text { regional park })\end{array}$ & -0.003 & $(0.018)$ & -0.018 & $(0.015)$ & & \\
\hline $\begin{array}{l}\log (\text { Distance to national, state, or } \\
\text { regional park }) \times \log (\text { Area })\end{array}$ & 0.006 & $(0.006)$ & 0.007 & $(0.006)$ & & \\
\hline $\log ($ Distance to the main road) & $-0.021 * *$ & $(0.009)$ & $-0.029 * * *$ & $(0.008)$ & & \\
\hline $\begin{array}{l}\log (\text { Distance to the main road }) \times \\
\log (\text { Area })\end{array}$ & $0.006^{* *}$ & $(0.003)$ & $0.007 * * *$ & $(0.002)$ & & \\
\hline $\log ($ Distance to the river) & $-0.018 * *$ & $(0.008)$ & $-0.018 * *$ & $(0.007)$ & & \\
\hline $\begin{array}{c}\log (\text { Distance to the river }) \times \\
\log (\text { Area })\end{array}$ & 0.003 & $(0.002)$ & 0.001 & $(0.002)$ & & \\
\hline $\log (\mathrm{PGI})$ & $0.124 * * *$ & $(0.035)$ & $0.097 * * *$ & $(0.032)$ & & \\
\hline $\log (\mathrm{PGI}) \times \log ($ Area $)$ & $0.023 *$ & $(0.012)$ & $0.030 * *$ & $(0.012)$ & & \\
\hline Trend & $0.090 * * *$ & $(0.003)$ & $0.077 * * *$ & $(0.003)$ & & \\
\hline Trend $\times \log ($ Area $)$ & $-0.011 * * *$ & $(0.001)$ & $-0.010 * * *$ & $(0.001)$ & & \\
\hline Spatial fixed effects & Yes & & & & & \\
\hline Spatio-temporal lag & & & $0.166 * * *$ & $(0.022)$ & & \\
\hline Spatial error & & & $0.878 * * *$ & $(0.035)$ & & \\
\hline Number of observations & 7205 & & 7205 & & & \\
\hline$R^{2}$ & 0.881 & & & & & \\
\hline Adjusted $R^{2}$ & 0.878 & & & & & \\
\hline Nagelkerke (1991) Pseudo $R^{2}$ & & & 0.878 & & & \\
\hline $\mathrm{AIC}$ & 12694 & & 12632 & & & \\
\hline $\begin{array}{l}\text { Breusch-Pagan test for } \\
\text { heteroskedasticity }\end{array}$ & $419.1 * * *$ & & $214.3 * * *$ & & & \\
\hline
\end{tabular}

Note: robust standard errors are in parentheses; $*$ Significant at $10 \%$ level; ${ }^{* *}$ significant at $5 \%$ level; $* * *$ significant at $1 \%$ level. 


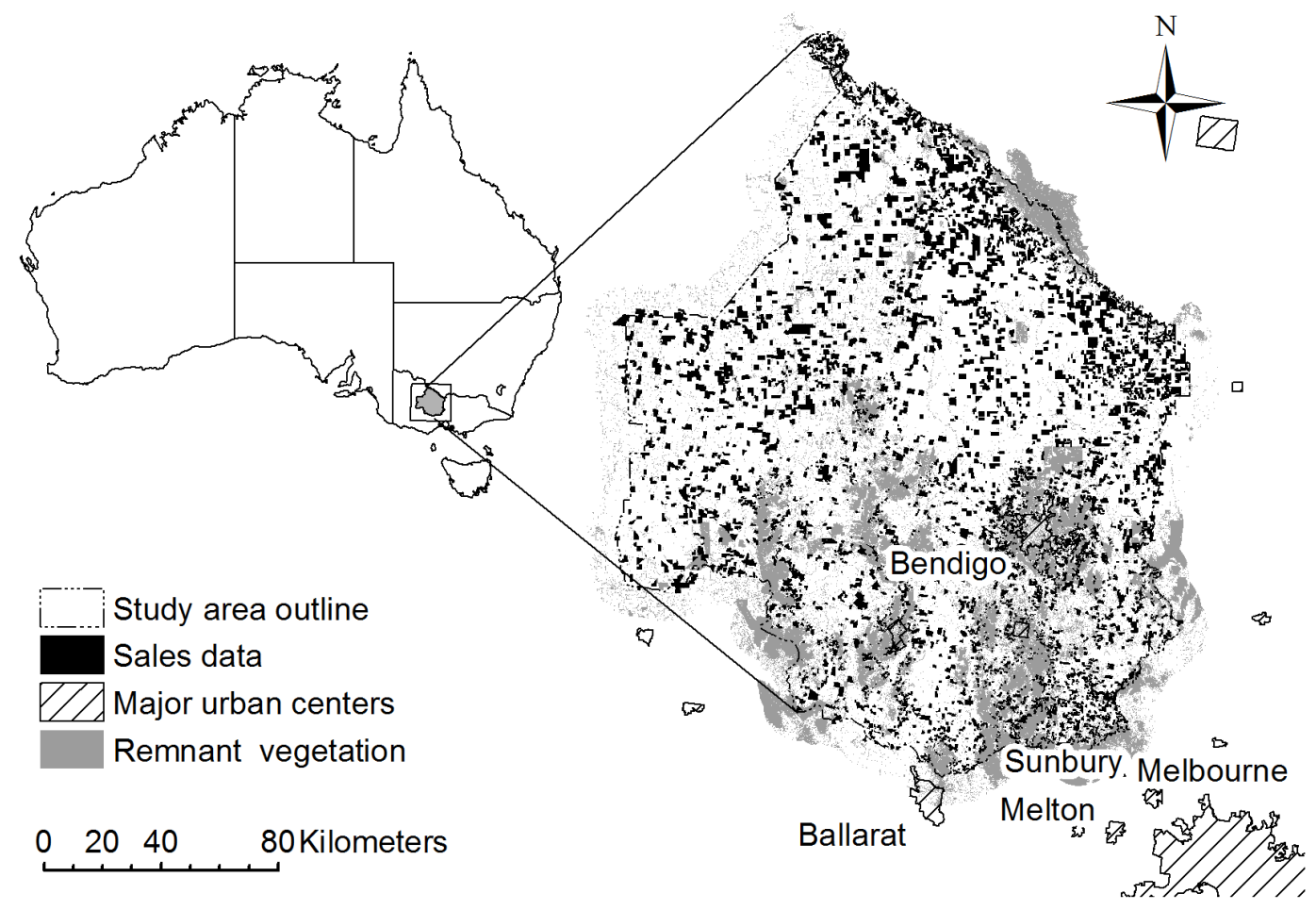

Figure 1. Location of the study area and sales data 
a)

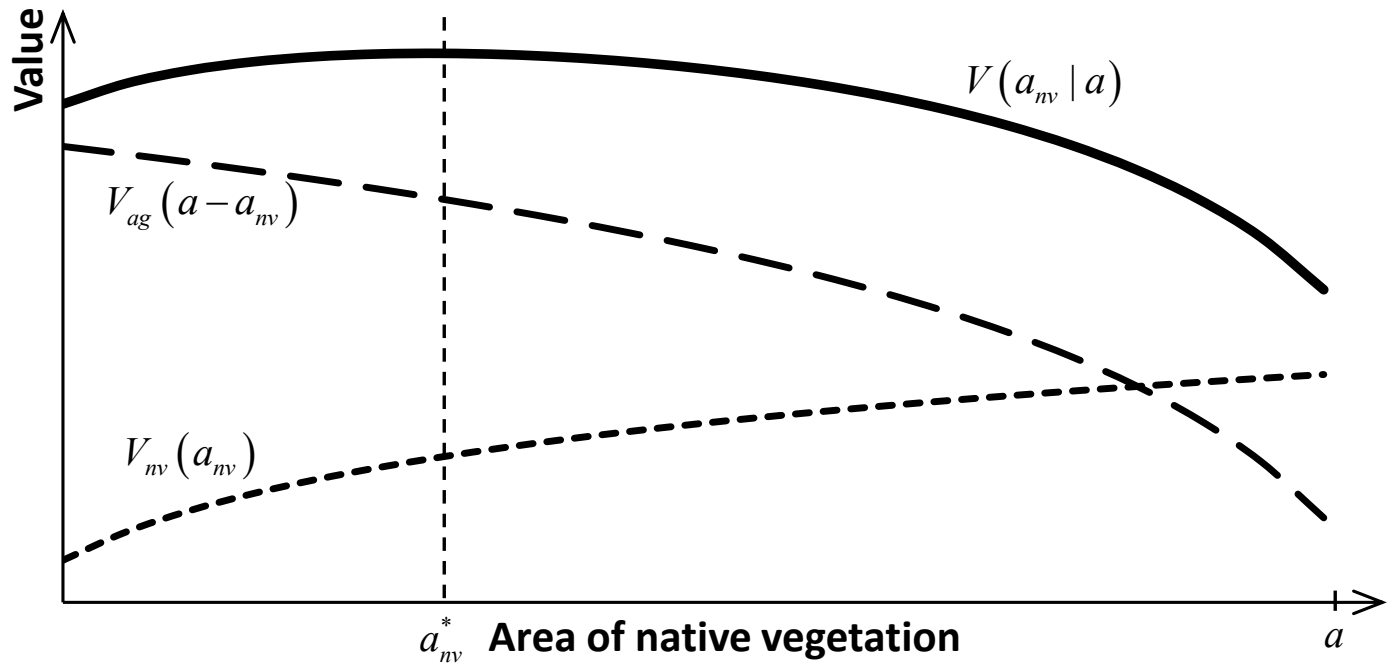

b)

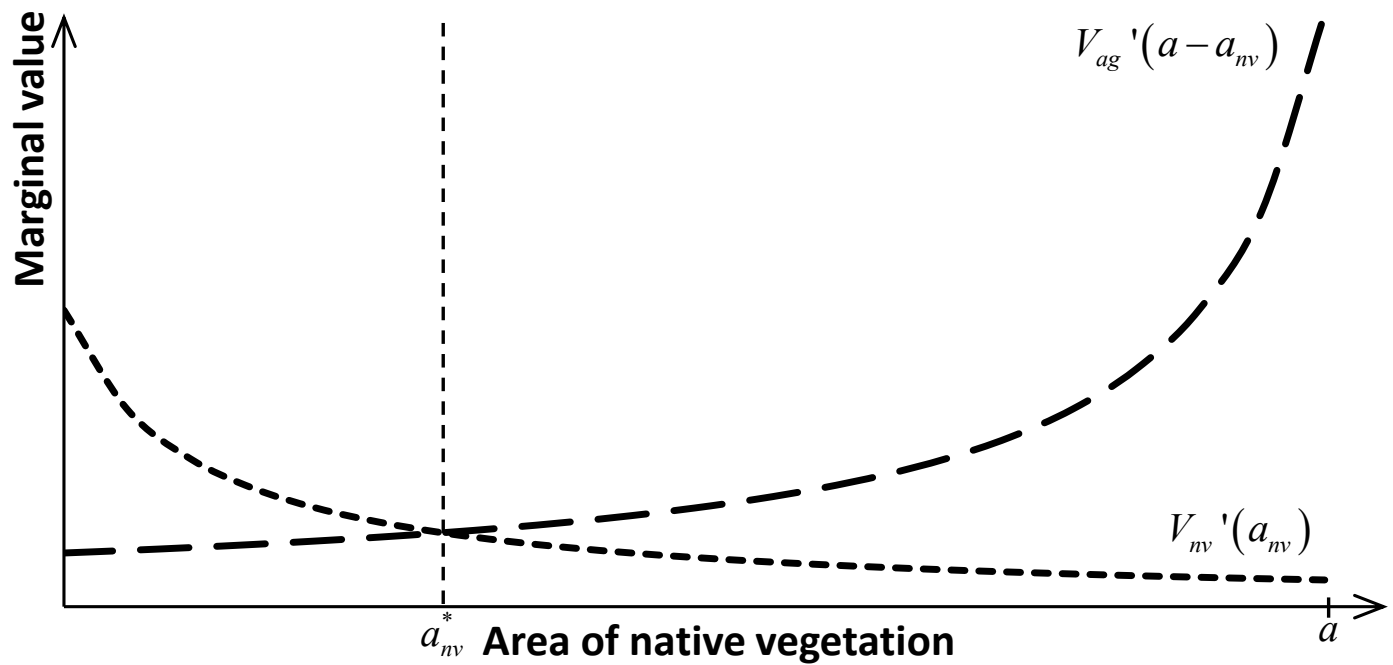

Figure 2. Marginal values and values of native vegetation and agricultural land 


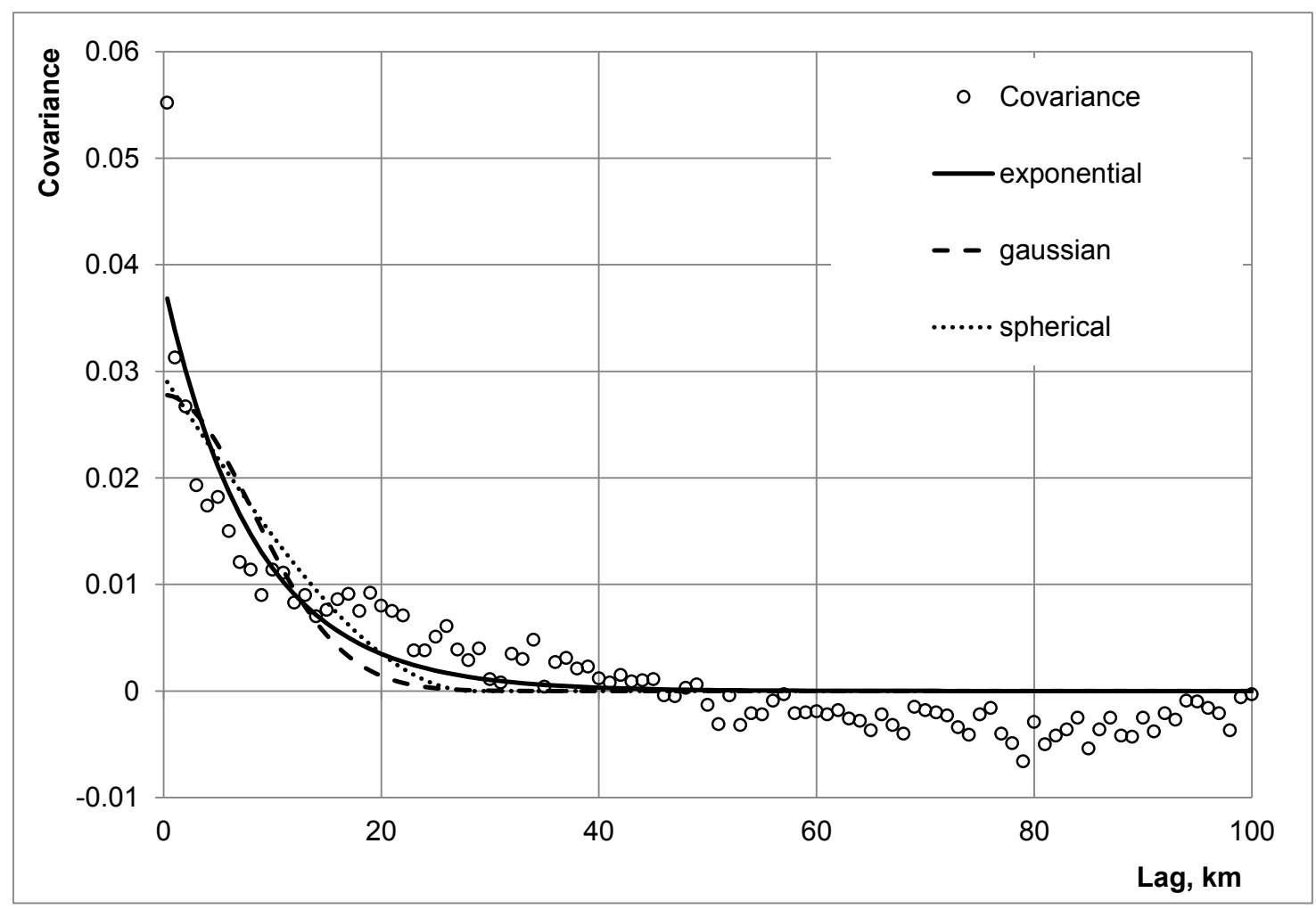

Figure 3. Empirical and fitted covariograms of the residuals from the OLS estimation of rural properties values model 
Spatial fixed effects

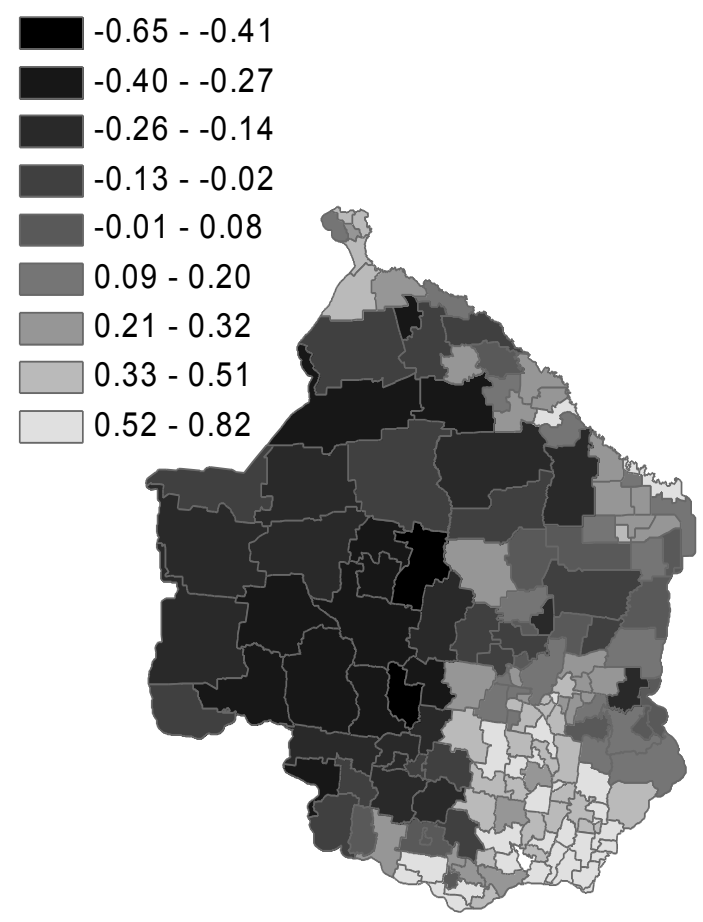

Spatially correlated residuals

- $-0.50--0.41$

- $\quad-0.40--0.27$

- $-0.26--0.14$

- $-0.13--0.02$

- $-0.01-0.08$

- $0.09-0.20$

- $0.21-0.32$

- $0.33-0.51$

$0.52-0.82$

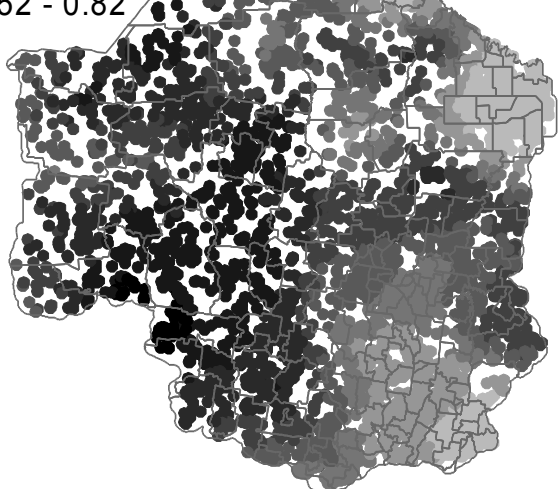

Figure 4. Fixed effects of the spatial fixed effects model and spatially correlated residuals of the Manski model with spatio-temporal lag 


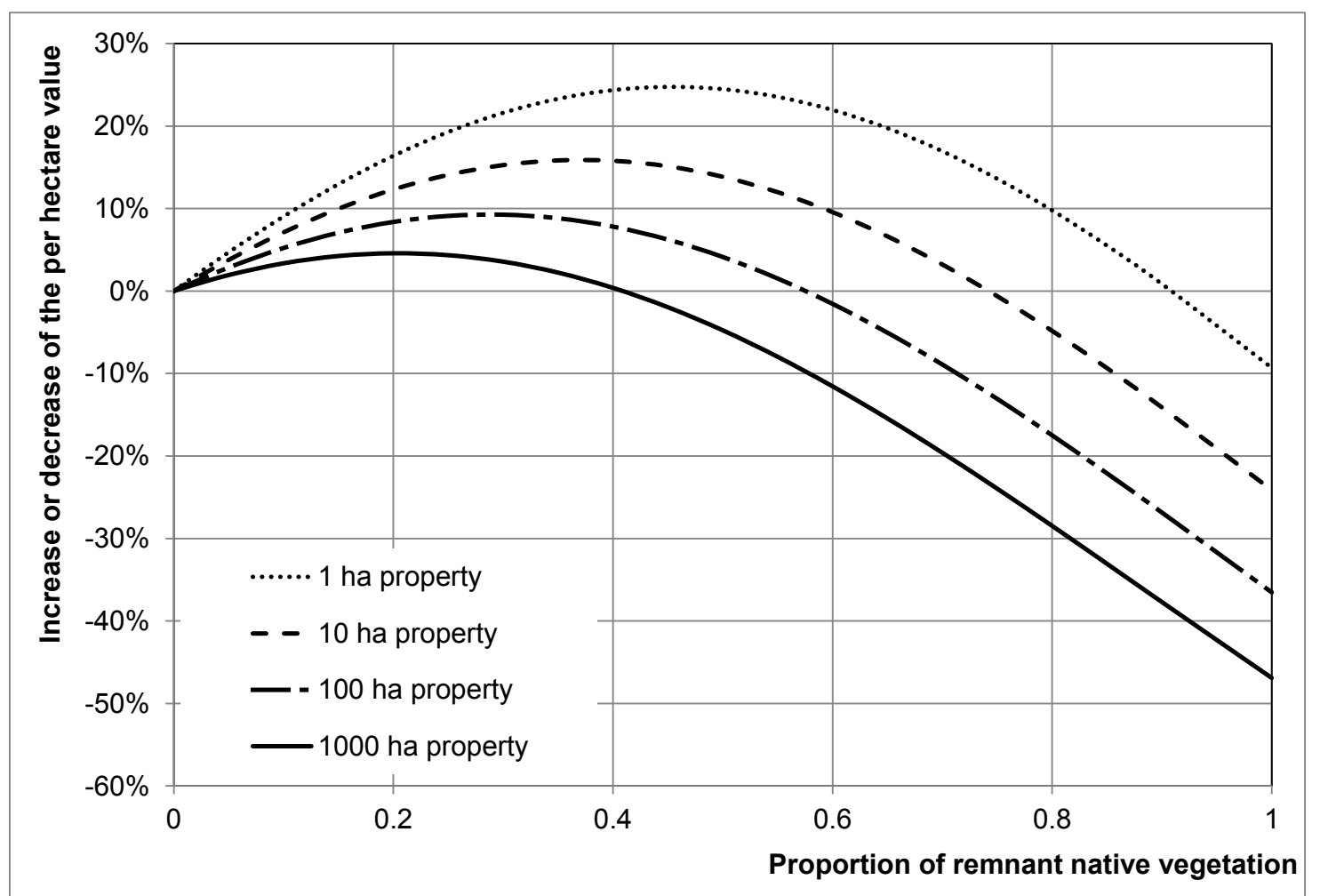

Figure 5. Effect of the proportion of native woody vegetation on land value by property size over time 


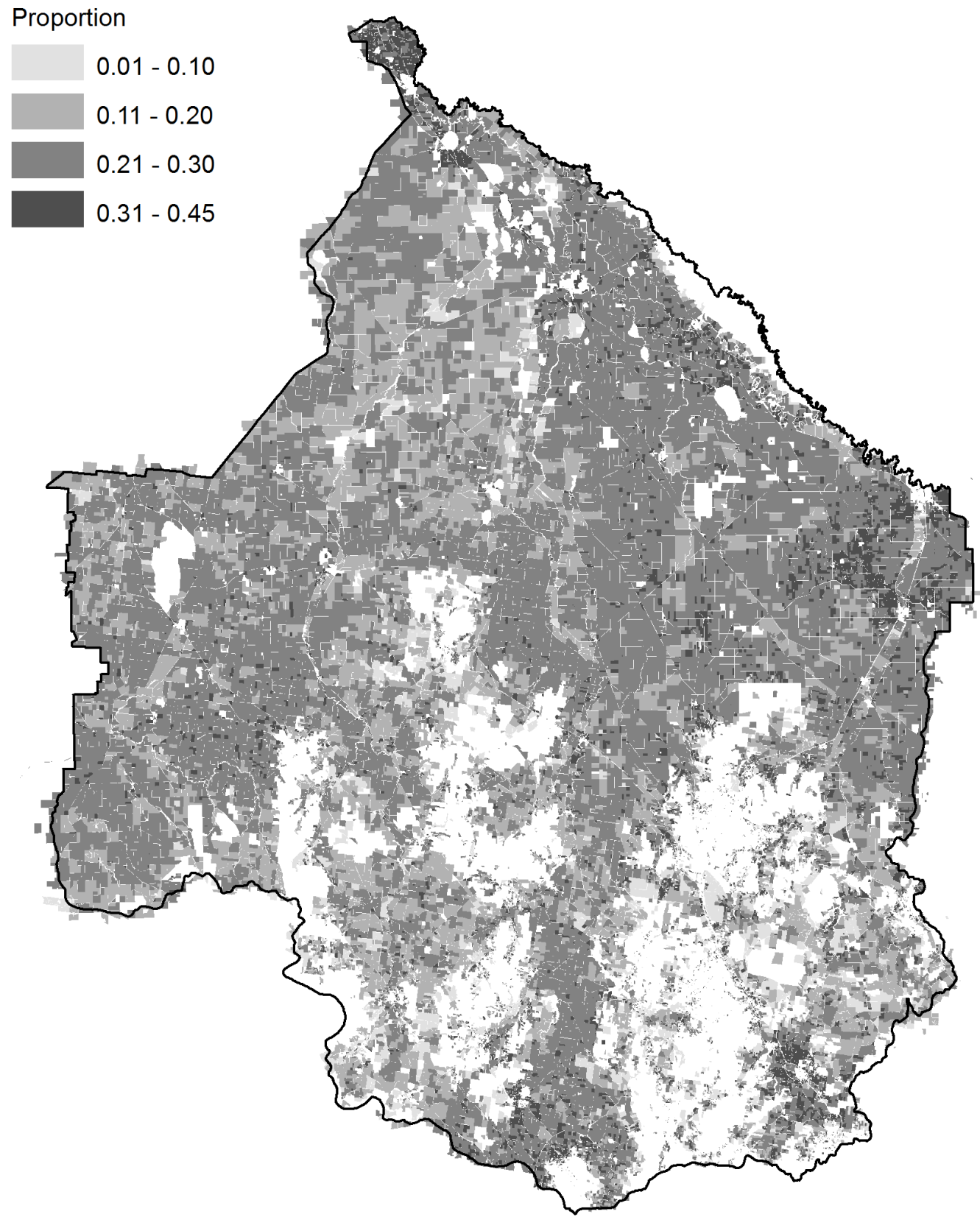

Figure 6. Additional proportion of native vegetation required to achieve predicted maximum property values 